\title{
A PROTEÇÃO AO INVESTIDOR NO CÓDIGO DE GOVERNANÇA CORPORATIVA ALEMÃO
}

\author{
Roberto de Araújo Chacon de Albuquerque
}

THE PROTECTION OF INVESTORS IN THE GERMAN CORPORATE GOVERNANCE CODE

\section{RESUMO}

Este artigo analisa o Código de Governança Corporativa ALEMÃO COMO UM INSTRUMENTO PARA AUMENTAR A CONFIANÇA DOS INVESTIDORES E DO PÚBLICO EM GERAL NO FUNCIONAMENTO DAS SOCIEDADES ANÔNIMAS. BASEADO EM PADRÕES ACEITOS NACIONAL E INTERNACIONALMENTE, O CÓDIGO CONTÉM RECOMENDAÇÕES QUE PROCURAM FAVORECER UMA COOPERAÇÃO MAIS EFICIENTE ENTRE A DIRETORIA E O

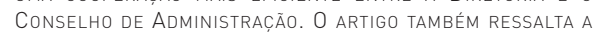
CONEXÃO ENTRE A GOVERNANÇA COOPERATIVA E A PROMOÇÃO DA TRANSPARÊNCIA NA ADMINISTRAÇÃO DAS EMPRESAS.

\section{PALAVRAS-CHAVE}

GOVERNANÇA CORPORATIVA, CÓDIGO, ALEMÃO.

\begin{abstract}
THIS ARTICLE ANALYZES THE GERMAN CORPORATE GOVERNANCE CODE AS A TOOL TO FOSTER THE CONFIDENCE OF INVESTORS AND THE GENERAL PUBLIC IN THE FUNCTIONING OF COMPANIES LISTED ON THE STOCK MARKET. BASED ON NATIONALLY AND INTERNATIONALLY ACCEPTED STANDARDS, THE CODE CONTAINS RECOMMENDATIONS THAT AIM AT FAVORING A MORE EFFICIENT COOPERATION BETWEEN THE BOARD OF DIRECTORS AND THE SUPERVISORY BOARD. THE ARTICLE ALSO HIGHLIGHTS THE CONNECTION BETWEEN CORPORATE GOVERNANCE AND THE PROMOTION OF TRANSPARENCY IN COMPANY MANAGEMENT. KEYWORDS

CORPORATE GOVERNANCE, CODE, GERMAN.
\end{abstract}

\section{SUMÁRIO:}

Introdução.

1. Código de Governança Corporativa alemão.

2. Medidas legislativas complementares.

3. Pontos críticos para a governança corporativa alemã.

3.1 Proteção insuficiente dos interesses dos acionistas.

3.2 Composição dual da direção das empresas, com Diretoria e Conselho de Administração.

3.3 Transparência insuficiente na direção das empresas.

3.4 Independência insuficiente do Conselho de Administração.

3.5 Independência restrita dos auditores.

Conclusão.

Bibliografia. 


\section{INTRODUÇÃO}

A Organização para Cooperação e Desenvolvimento Econômico (OCDE), ao aprovar os Princípios de Governança Corporativa, conferiu ao tema uma abalizada projeção internacional. Publicados pela primeira vez em 1998 e atualizados em 2004, os Princípios tornaram-se um modelo no qual os mais variados países têm buscado inspiração para modernizar sua legislação. A governança corporativa tem como objetivo assegurar que se tenha um negócio de qualidade, lucrativo e bem administrado, aumentando seu valor perante a sociedade. Ao estimular uma gestão mais responsável, facilita-se o acesso das sociedades anônimas ${ }^{2}$ ao crédito disponível no mercado.

A governança corporativa engloba a série de procedimentos mediante os quais uma sociedade anônima é dirigida, administrada ou controlada. O objetivo, com a adoção dessa série de procedimentos, é aumentar o valor de mercado da sociedade, facilitando seu acesso ao capital disponível no mercado ao combater abusos e corrupção. A governança corporativa, ao conferir mais transparência e eficiência à gestão das sociedades anônimas, dá uma nova dimensão ao relacionamento entre seus principais players, os acionistas, a Diretoria e o Conselho de Administração. ${ }^{3}$ Instrumentos de fiscalização e de controle da gestão das sociedades anônimas devem ser adotados, dentro de um contexto no qual seja prevista a atuação independente do Conselho de Administração, para que seja assegurada a fiscalização da Diretoria com ampla transparência e prestação de contas.

Para os Princípios de Governança Corporativa da OCDE, é fundamental que as empresas por ações sejam adequadamente dirigidas e fiscalizadas, inclusive no que diz respeito ao relacionamento entre si dos órgãos que compõem as sociedades anônimas, como a Diretoria e o Conselho de Administração, e às relações mantidas pelas empresas com seus próprios acionistas e investidores. A própria superação do chamado "conflito de agência”, provocado pela separação entre a propriedade e a gestão da empresa, é um dos objetivos maiores da governança corporativa. O titular da propriedade delega a um agente o poder de decisão sobre a gestão da empresa. Surgem, então, conflitos de agência, conflitos de poder entre quem administra a empresa e quem é seu proprietário. Nem sempre os objetivos e interesses do titular da propriedade e do administrador da propriedade são os mesmos. ${ }^{4}$

A principal meta é colocar em prática mecanismos eficientes, como sistemas de fiscalização, que assegurem a compatibilidade entre as atividades desempenhadas pelos executivos e os interesses dos acionistas. Os Princípios de Governança Corporativa da OCDE visam proporcionar aos proprietários das sociedades por ações, ${ }^{5}$ os acionistas, maior controle sobre a gestão da empresa contra abusos de poder do acionista controlador sobre acionistas minoritários, do Conselho de Administração sobre os acionistas; contra erros estratégicos, provocados pelo poder concentrado em uma só pessoa, normalmente o executivo principal; e contra fraudes, 
com a utilização de informação privilegiada em benefício próprio. Para que se supere o conflito de agência, é necessário que se confiram aos proprietários das sociedades anônimas instrumentos jurídicos que fomentem a governança corporativa, permitindo-lhes descortinar, fiscalizando e avaliando, o funcionamento das empresas. ${ }^{6}$

A Comissão Governamental, instituída pelo Ministério da Justiça alemão em setembro de 2001, adotou, em 26.02.2002, o Código de Governança Corporativa, ${ }^{7}$ um instrumento jurídico baseado nos Princípios de Governança Corporativa da OCDE que pretende ajudar a superar o conflito de agência na Alemanha. O Código, graças ao previsto na Lei das Sociedades Anônimas, ${ }^{8}$ art. 161 , com a redação que lhe foi conferida pela Lei de Transparência e Publicidade, ${ }^{9}$ possui força cogente. ${ }^{10}$ Ele não constitui apenas um código de auto-regulação. O Código de Governança Corporativa faz parte integrante do ordenamento jurídico alemão. A Comissão Governamental permanece ativa, mesmo após a promulgação do Código. Ela acompanha sua colocação em prática pelas sociedades por ações, possibilitando a reflexão sobre eventuais atualizações em seu texto. Ao menos uma vez por ano, a Comissão Governamental verifica se o Código de Governança Corporativa precisa ser adaptado. ${ }^{11}$

Com o Código, as normas de direção e fiscalização das sociedades anônimas, tanto para investidores nacionais como estrangeiros, devem tornar-se mais transparentes, de maneira a fortalecer a confiança no funcionamento das empresas alemãs. Ele disciplina todos os assuntos críticos essenciais, sobretudo sob o ponto de vista internacional, no que diz respeito à estrutura das sociedades por ações daquele país, fundamentalmente: (1) proteção insuficiente dos interesses dos acionistas; (2) composição dual da direção das empresas, com Diretoria e Conselho de Administração; ${ }^{12}$ (3) transparência insuficiente na direção das empresas; (4) independência insuficiente do Conselho de Administração; e (5) independência restrita dos auditores. Os dispositivos do Código de Governança Corporativa alemão disciplinam cada um destes pontos críticos. Ele, evidentemente, não pode versar, em profundidade, sobre cada um desses aspectos, mas estabelece uma orientação sobre o que deve ser feito a respeito pelas sociedades por ações para que se tenha um negócio de qualidade, lucrativo e bem administrado, capaz de atrair o interesse do mercado de capitais internacional. O Código contém os dispositivos essenciais para a direção e fiscalização das sociedades anônimas, sob a forma de recomendações, levando em consideração padrões reconhecidos nacional e internacionalmente. Seu objetivo primordial é promover o funcionamento das empresas alemãs de uma forma transparente.

\section{Código alemão de Governança Corporativa}

A governança corporativa na Alemanha tem bases sólidas, mas tem sido preciso adaptá-la ao paradigma de governança corporativa anglo-americano. Mesmo os investidores 
asiáticos têm como referência a perspectiva anglo-americana, e não a alemã. O objetivo do Código de Governança Corporativa é tornar a Alemanha um lugar atraente para os investidores estrangeiros, que, tradicionalmente, têm demonstrado desconfiança no que concerne ao sistema dual de gestão das sociedades por ações alemãs, à interação entre a Diretoria e o Conselho de Administração nas empresas daquele país. O Código não constitui um exemplo isolado no esforço de promoção da governança corporativa na Alemanha. A Lei de Controle e Transparência no Ambiente Empresarial, ${ }^{13}$ por exemplo, aprimorou consideravelmente a dinâmica das sociedades por ações, sob o ponto de vista de sua direção e fiscalização. Mas um dos maiores problemas para o investidor estrangeiro é, justamente, que eles consideram a legislação alemã sobre sociedades por ações confusa. A quantidade de leis é muito grande. Além da própria Lei das Sociedades Anônimas, a Lei do Comércio de Títulos de Crédito, ${ }^{14}$ o Código Comercial ${ }^{15}$ e a Lei de Co-Gestão ${ }^{16}$ também disciplinam aspectos que, direta ou indiretamente, dizem respeito às sociedades por ações. Eles não têm sido considerados suficientes pelo investidor estrangeiro no que diz respeito ao estímulo à transparência da direção e fiscalização das empresas. As disposições do Código, levando em consideração esta crítica, são curtas e precisas, sendo de fácil compreensão até mesmo para leigos no assunto. Elas condensam as regras principais da governança corporativa, podendo ser compreendidas tanto por empresários como por investidores. O Código contém apenas cerca de 12 páginas.

O Código alemão de Governança Corporativa é um marco na assunção, por parte dos próprios agentes econômicos, de suas responsabilidades junto ao mercado financeiro. Ele complementa, indo além do soft law, do direito sem coercitividade imediata, o disposto na Lei de Transparência e Publicidade, que consagra o princípio comply or explain. ${ }^{17}$ Esta lei prevê a necessidade de o Código ser observado. Quer-se que as sociedades alemãs por ações correspondam ao seu real valor de mercado. Adotaram-se normas claras para a Diretoria e o Conselho de Administração naquilo que diz respeito, por exemplo, à divulgação de conflitos de interesse, à instituição de comissões, com o objetivo de aumentar a transparência inclusive na compra e venda de ações da sociedade anônima, tendo sempre em vista a melhora do acesso das empresas alemãs aos recursos do mercado de capitais internacional. O Código consagra várias recomendações para incrementar a confiança do investidor estrangeiro nas sociedades por ações alemãs.

A necessidade de promoção da governança corporativa não constitui um fato isolado, tampouco consumado. A crise nas bolsas de valor americanas, o escândalo envolvendo fraudes em sociedades por ações, como a gigante de energia americana Enron, ${ }^{18}$ prejudicaram a credibilidade do mercado de capitais. A promoção da governança corporativa envolve um esforço constante tanto do legislador como dos agentes econômicos na melhora não apenas dos princípios em que ela se assenta, 
como de sua colocação em prática. Tanto nacional como internacionalmente, desenvolvem-se, e aperfeiçoam-se, os fundamentos da governança corporativa. O Código de Governança Corporativa precisará ser constantemente adaptado a tais padrões. Ele não tem nem terá uma feição definitiva. A Comissão Governamental, conforme já se pôde ressaltar, reúne-se, ao menos uma vez por ano, para efetuar as adaptações necessárias ao Código, levando em consideração o desenvolvimento do assunto. A Comissão, convocada pelo Ministério da Justiça alemão, tem em sua composição investidores institucionais e privados; membros da Diretoria e de Conselhos de Administração de sociedades por ações; representantes de trabalhadores, bem como da comunidade científica e funciona com independência em relação ao Ministério da Justiça. O Código uniformiza os princípios da governança corporativa para as sociedades alemãs por ações.

A principal missão da Comissão tem sido condensar, em um único instrumento jurídico, as recomendações essenciais para a direção e fiscalização das sociedades anônimas, levando em conta princípios reconhecidos nacional e internacionalmente, com o objetivo de estimular a administração responsável das empresas alemãs. A Comissão Governamental, após a redação do Código de Governança Corporativa, monitora sua colocação em prática, de maneira que a práxis da direção das empresas seja fiscalizada, bem como procede ao exame anual de suas próprias recomendações. O Código é um catálogo de referências sobre o estado da arte da governança corporativa. Não apenas sociedades por ações alemãs, mas também estrangeiras, e representantes da política, economia, sindicatos, meios de comunicação, mercado de capitais contribuíram para sua feitura. Quer-se que a valorização das empresas alemãs na bolsa de valores corresponda ao seu valor efetivo, evitandose fraudes como a que vitimou os acionistas da gigante de energia americana Enron. O Código tem o mérito de resumir o que várias leis e regulamentos contêm, de forma dispersa, a respeito da governança corporativa. Esta tem uma longa tradição na Alemanha, que precisará ser constantemente adaptada. A Comissão levou em consideração os pontos críticos na direção e fiscalização das sociedades por ações na Alemanha, sempre à luz da estrutura econômica daquele país, procurando encontrar soluções para problemas concretos. Não se incorporou, literalmente, a crítica internacional à governança corporativa alemã.

Nem todas as sociedades por ações aceitarão integralmente as recomendações do Código; algumas acatarão tais ou quais recomendações, já que elas podem não se adequar ao perfil da respectiva empresa. Uma recusa bem fundamentada das recomendações do Código não constitui, necessariamente, uma mácula para a governança corporativa de uma empresa. Serão os comunicadores e operadores do mercado de capitais, como os jornalistas e analistas, que decidirão como avaliar tais recusas. A Lei das Sociedades Anônimas (art. 161) obriga toda sociedade por ações que não queira cumprir o previsto no Código de Governança Corporativa alemão a 
justificar-se perante o público e investidores. As normas claras do Código para a Diretoria e o Conselho de Administração, ao aumentar a transparência para os investidores tanto no que diz respeito ao seu funcionamento interno como à inter-relação entre esses órgãos, devem facilitar o acesso das empresas alemãs aos recursos do mercado de capitais internacional.

A questão da aquisição de empresas, por exemplo, é de importância fundamental. O legislador alemão já procurou discipliná-la na Lei de Aquisição de Títulos de Crédito e de Aquisição de Empresas. ${ }^{19}$ Esta lei remete ao dever de neutralidade da Diretoria em seu art. 33, muito criticado pelo mercado de capitais, que o considerou pouco preciso. A Comissão Governamental, neste particular, preferiu consignar no Código de Governança Corporativa que se deve levar a consulta, junto à Assembléia Geral, questões como a da aquisição de empresas. A Assembléia Geral, portanto, deve ser consultada não apenas nos casos previstos expressamente em lei. Mesmo quando não for necessário legalmente, deve-se consultar a Assembléia Geral, em benefício da transparência. É necessário, neste aspecto, levar em consideração também a antiga discussão sobre a aquisição de empresas no seio da União Européia, com a proposta de uma diretiva comunitária sobre o assunto. ${ }^{20}$ A reação dos investidores ao previsto no Código de Governança Corporativa alemão sobre a aquisição de empresas constituirá um indicador importante no tocante à aceitação do próprio Código.

\section{Medidas legislativas COMPlementares}

A promoção da governança corporativa na Alemanha não se esgota com a adoção do respectivo Código. Ela requer a reforma da Lei das Sociedades Anônimas, bem como normas ainda mais específicas sobre a aquisição de empresas, que aperfeiçoem a proteção do acionista minoritário. Uma parte dessa tarefa já foi assumida pelo legislador, com a Lei de Estímulo ao Mercado de Capitais ${ }^{21}$ e a Lei de Transparência e Publicidade.

O Código de Governança Corporativa alemão está ancorado na Lei de Transparência e Publicidade, na redação que conferiu ao art. 161 da Lei das Sociedades Anônimas. Ela obriga a Diretoria e o Conselho de Administração das sociedades por ações a declarar, anualmente, se as recomendações do Código foram cumpridas, declaração que deve ser divulgada aos acionistas. As sociedades anônimas têm a opção de declarar que cumprem as recomendações do Código de Governança Corporativa ou elucidar por que não desejam cumpri-las. As recomendações gozam, portanto, de obrigatoriedade, ainda que limitada. Não se prevê, na Lei de Transparência e Publicidade, uma inspeção das atividades da Diretoria e do Conselho de Administração, para verificar se elas estão de acordo com o previsto no Código. Esta inspeção poderá, no entanto, ser levada a cabo por auditores independentes com 
o objetivo de comprovar se as recomendações têm sido efetivamente cumpridas. O próprio mercado de capitais também pode avaliar, periodicamente, por seus próprios meios, o cumprimento do previsto no Código de Governança Corporativa alemão. Esta espécie de verificação difusa pode terminar sendo a mais eficaz, de maior efeito dissuasivo.

A Lei de Transparência e Publicidade entrou em vigor em 26.07.2002. Adotouse, à luz do previsto em seu art. $1 .^{\circ}, \S 16$, uma nova redação para o art. 161 da Lei das Sociedades Anônimas, com esclarecimentos sobre a obrigatoriedade do Código de Governança Corporativa:

A Diretoria e o Conselho de Administração das sociedades por ações declararão anualmente se as recomendações da "Comissão Governamental do Código de Governança Corporativa alemão”, publicadas pelo Ministério Federal da Justiça na seção administrativa do Diário Oficial eletrônico, foram ou serão cumpridas, ou quais recomendações não foram ou não serão adotadas. A declaração será colocada duradouramente à disposição dos acionistas. ${ }^{22}$

O art. 3. ', § 2. ', “3”, da Lei de Transparência e Publicidade contém um dispositivo relativo ao art. 161 da Lei das Sociedades Anônimas que passou a constar do art. 15 da Lei de Introdução à Lei das Sociedades Anônimas: ${ }^{23}$

A declaração prevista no art. 161 da Lei das Sociedades Anônimas será entregue pela primeira vez no ano de 2002. ${ }^{24}$ Ela poderá neste ano restringir-se a se as recomendações da "Comissão Governamental do Código de Governança Corporativa alemão” serão cumpridas ou quais recomendações não serão adotadas. ${ }^{25}$

Após a adoção do Código, o legislador disciplinou, no art. 15a da Lei do Comércio de Títulos de Crédito, a divulgação da compra e venda de ações da empresa por membros da Diretoria e do Conselho de Administração. ${ }^{26}$ Assim, a recomendação do Código de Governança Corporativa alemão, art. 6.6., § 1. ${ }^{\circ},{ }^{27}$ revestiu-se de maior obrigatoriedade e foi reforçada pelo disposto no art. 15a da Lei do Comércio de Títulos de Crédito.

\section{Pontos Críticos para A governança corporativa Alemã}

A Comissão Governamental trabalhou baseada no consenso de que o Código de Governança Corporativa só terá sucesso se não se restringir às normas de governança corporativa tradicionalmente vigentes na Alemanha. Levou-se em consideração, desde o início, a crítica à governança corporativa alemã sob uma perspectiva internacional, 
as queixas dos investidores estrangeiros com respeito ao funcionamento das sociedades por ações naquele país. O Código, conforme pudemos assinalar anteriormente, trata dos pontos críticos essenciais, sempre do ponto de vista internacional, no que diz respeito à dinâmica das sociedades anônimas, fundamentalmente: (1) proteção insuficiente dos interesses dos acionistas; (2) composição dual da direção das empresas, com Diretoria e Conselho de Administração; (3) transparência insuficiente na direção das empresas; (4) independência insuficiente do Conselho de Administração; e (5) independência restrita dos auditores. Cada um destes aspectos será analisado a seguir.

\section{I ProteçÃo insuficiente dos interesses dos ACIONistas}

O primeiro capítulo do Código trata, especificamente, dos acionistas e da Assembléia Geral. Os interesses dos acionistas, os proprietários das sociedades anônimas, são alvo de proteção específica. Os direitos individuais de participação dos acionistas na Assembléia Geral e, especialmente, o direito de voto, de acordo com o princípio one share, one vote, ${ }^{28}$ são consagrados, bem como a competência da Assembléia Geral na deliberação de questões essenciais às sociedades por ações. Sobretudo para o investidor estrangeiro, isto é de fundamental importância. Uma de suas maiores queixas, com relação à governança corporativa alemã, consiste, justamente, em que aos acionistas deve ser facilitado o exercício de seus direitos, sobretudo do direito de voto.

O Código de Governança Corporativa alemão prevê que as sociedades anônimas devem providenciar instruções sobre a instituição de representantes com direito de voto na Assembléia Geral (Código, art. 2.3.3). ${ }^{29}$ Elas também devem permitir aos acionistas acompanhar a Assembléia Geral via internet (Código, art. 2.3.4). ${ }^{30}$ No tocante ao tema, muito discutido, das medidas de proteção contra propostas de aquisição, o Código prevê que a Diretoria deve convocar uma Assembléia Extraordinária na qual os acionistas se informarão sobre a proposta, podendo, ainda, decidir que medidas poderão adotar contra ela (Código, art. $3.7, \S 3 .^{\circ}$ ). ${ }^{31}$

\subsection{COMPOSIÇÃO DUAL DA DIREÇÃo DAS EMPRESAS, Com Diretoria e Conselho de Administração}

A Diretoria, ${ }^{32}$ na Alemanha, dirige a empresa e seu presidente ${ }^{33}$ coordena as respectivas atividades. O Conselho de Administração ${ }^{34}$ fiscaliza e aconselha a Diretoria, envolvendo-se diretamente em decisões fundamentais para a empresa. O presidente do Conselho de Administração também coordena o trabalho na sua esfera de atuação. A co-gestão exige que, de acordo com o tamanho da empresa, até a metade dos membros do Conselho de Administração seja representante dos trabalhadores.

Prevalece, fora da Alemanha, nos países que não seguiram o modelo de composição dual, um sistema no qual a direção e fiscalização das empresas se efetua 
predominantemente mediante um órgão unitário, o Board of Directors anglo-americano ou o Conseil d'administration francês. Os membros de tais órgãos reúnem-se com freqüência e compartilham intensamente informações sobre a empresa na qual trabalham. O presidente da Diretoria ${ }^{35}$ de uma sociedade por ações alemã e de um Board of Directors anglo-americano desempenham basicamente, no entanto, as mesmas funções. Em um Board of Directors, também há a diferença entre membros diretivos e não diretivos. Na França, as empresas podem dispor, com apoio na lei, para sua direção, de uma Diretoria, ${ }^{36}$ com funções diretivas, e de um Conselho de Administração. ${ }^{37}$ Na prática, o sistema é dual, tanto na Alemanha como nos Estados Unidos e na França. O Boardsystem anglo-americano e o Verwaltungsratsystem ${ }^{38}$ alemão, ambos, dispõem de um sistema dual de direção e fiscalização nas sociedades por ações.

O Código de Governança Corporativa alemão fomenta o trabalho conjunto da Diretoria e do Conselho de Administração, bem como uma discussão aberta e intensa de questões empresariais no próprio Conselho de Administração, estimulando, assim, o intercâmbio de informações entre os dois órgãos (Código, Capítulo III). Ele também trata do repasse de informações ao Conselho de Administração e dispõe sobre o fornecimento de relatórios escritos, de maneira pontual, por parte da Diretoria. O Código acentua que o Conselho de Administração não deve restringirse, no exercício de suas atividades, à análise de relatórios que lhe forem encaminhados pela Diretoria. Muito pelo contrário, tanto a Diretoria como o Conselho de Administração devem assumir, reciprocamente, suas responsabilidades no que diz respeito ao dever de informar e relatar.

O Conselho de Administração deve assumir um papel ativo na fiscalização do funcionamento da empresa (Código, art. $3.4, \S 1 .^{\circ}$ ), ${ }^{39}$ o que não será alcançado sem o aperfeiçoamento da cultura de discussão no interior do próprio Conselho de Administração. Prevê-se a instituição mais freqüente de comissões (Código, art. 5.3) (0 $^{40}$ e consultas regulares a acionistas e terceiros ${ }^{41}$ antes das reuniões do Conselho de Administração (Código, art. 7.1.1). ${ }^{42}$ Para uma discussão mais aberta no Conselho de Administração, bem como para um intercâmbio de opiniões entre a Diretoria e o Conselho de Administração, a observação estrita da confidencialidade é de fundamental importância. Ninguém prestará informações se temer que, no dia seguinte, elas serão divulgadas à imprensa. O Código apóia a observação estrita da confidencialidade (Código, art. 3.5, § 1..$\left.^{\circ}\right) .^{43} \mathrm{O}$ Código de Governança Corporativa alemão deixa claro quais são as tarefas e competências do presidente do Conselho de Administração:

O presidente do Conselho de Administração deverá manter contato regular com a Diretoria, especialmente com o presidente, ou, se for o caso, com o representante da Diretoria, e, com ele, discutir a estratégia, o desenvolvimento da sociedade e a gestão dos riscos da empresa. O presidente do Conselho de Administração será informado imediatamente pelo presidente da Diretoria, ou, 
se for o caso, pelo representante da Diretoria, com relação aos acontecimentos importantes que forem de significado essencial para a avaliação da situação e desenvolvimento, bem como da direção da empresa. O presidente do Conselho de Administração deverá, então, informar o Conselho de Administração e convocar, se for necessário, uma reunião extraordinária do Conselho de Administração ${ }^{44}$ (Código, art. 5.2, § 3. ${ }^{\circ}$ ). ${ }^{45}$

Se a Diretoria e o Conselho de Administração obedecerem às normas estabelecidas pelo Código, a diferença, na prática, entre o funcionamento do Boardsystem anglo-americano e do Verwaltungsratsystem alemão deixará de existir.

\subsection{TRANSPARÊNCIA INSUFICIENTE NA DIREÇÃO DAS EMPRESAS}

O estímulo à transparência é um dos principais objetivos do Código. Na prática, cada empresa tem, de acordo com sua situação específica, mecanismos próprios de fiscalização. O objetivo do Código não é uniformizar tais mecanismos, mas conferir-lhes clareza, de maneira que o mercado de capitais possa conceber uma imagem precisa do funcionamento da empresa. O Código de Governança Corporativa alemão procura conferir transparência à empresa, à sua direção e fiscalização, bem como ao sistema de remuneração dos membros dos órgãos diretivos e à percepção de lucros. Como ressaltamos anteriormente:

Acionistas e terceiros serão informados sobretudo através do balanço consolidado da empresa. Eles deverão ser informados durante o ano fiscal através de relatórios parciais. O balanço consolidado da empresa e os relatórios parciais deverão ser redigidos levando em consideração princípios de contabilidade reconhecidos internacionalmente. Para fins da normativa societária (cálculo de dividendos, proteção dos credores), o balanço anual será redigido de acordo com o previsto na normativa nacional (Código Comercial), que também é base para a tributação (Código, art. 7.1.1). ${ }^{46}$

Balanços consolidados e relatórios parciais devem ser colocados com rapidez à disposição dos acionistas e investidores. Para os balanços consolidados, recomendase um prazo de "90 dias após o final do ano fiscal", e, para os relatórios parciais, um prazo de "45 dias após o final do respectivo período", ao qual o relatório diga respeito (Código, art. 7.1.2). ${ }^{47}$ As sociedades por ações devem tratar de maneira igual os acionistas ao prestar-lhes informações, bem como prestar-lhes informações à disposição sem demora, oferecendo-as via internet (Código, art. 6.4). ${ }^{48}$

A remuneração dos membros da Diretoria será fixada pelo Conselho de Administração [...] com base numa avaliação de desempenho. Critérios para 
a adequação da remuneração são, especialmente, as atribuições dos respectivos membros da Diretoria, seu desempenho pessoal, o desempenho da Diretoria, bem como a situação econômica, os resultados e as previsões quanto ao futuro da empresa, levando em consideração as empresas em funcionamento no mesmo setor (Código, art. 4.2.2, § 2. ${ }^{\circ}$ ). ${ }^{49}$

A composição variável da remuneração deve conter componentes com efeito de incentivo de longo prazo, o que diz respeito, por exemplo, a stock options ${ }^{50}$ e phantom stocks ${ }^{51}$ (Código, art. 4.2.3, § 2. ${ }^{\circ}$ ). ${ }^{52}$ Não se devem adotar, a título de composição variável da remuneração, títulos de crédito ${ }^{53}$ (Código, art. 4.2.4). ${ }^{54} \mathrm{O}$ sistema de remuneração do Conselho de Administração, previsto no Código de Governança Corporativa, também adota a avaliação de desempenho. O Código incentiva o engajamento acentuado e intenso dos membros do Conselho de Administração na fiscalização da empresa. Recomenda-se, assim, que não apenas o presidente como o seu representante no Conselho de Administração, à maneira do presidente e dos membros das Comissões, sejam especialmente remunerados. Isto estimula o cumprimento das atribuições que lhes são conferidas. O Código propõe que os membros do Conselho de Administração recebam uma "remuneração orientada pelo desempenho", que leve em consideração os resultados alcançados pela empresa a longo prazo (Código, art. 5.4.5, $\left.\S 2 .^{\circ}\right) .^{55}$

\section{3·4 IndePendênCia insuficiente do CONSElho de AdministraçÃo}

O Código de Governança Corporativa alemão contém, em várias de suas partes constitutivas, recomendações que asseguram a independência do Conselho de Administração. Não devem fazer parte do Conselho de Administração mais do que "dois ex-membros da Diretoria”, e os membros do Conselho de Administração "não deverão exercer nenhuma função diretiva nem de consultoria em concorrentes importantes da empresa" (Código, art. 5.4.2). ${ }^{56}$ O presidente do Conselho de Administração "não deve ser presidente da Comissão de Controle Interno" (Código, art. 5.2, § $2^{\circ}$ ). ${ }^{57}$ "O presidente da Comissão de Controle Interno não deve ter sido ex-membro da Diretoria da sociedade” (Código, art. 5.3.2). ${ }^{58}$ Tudo isso reforça a independência do Conselho de Administração.

Para assegurar que os membros do Conselho de Administração disponham de tempo suficiente para o exercício de seus mandatos, o Código de Governança Corporativa alemão recomenda que os membros da Diretoria não assumam "ao todo mais do que cinco mandatos em Conselhos de Administração em outras sociedades por ações estranhas à empresa" (Código, art. 5.4.3). ${ }^{59}$ No que diz respeito a conflitos de interesse, o Código também assume uma posição clara em favor da transparência e publicidade: 
Todo membro do Conselho de Administração deverá informar conflitos de interesse ao Conselho de Administração, especialmente aqueles que possam surgir com base na consultoria ou função diretiva junto a clientes, fornecedores, credores ou outros parceiros de negócio (Código, art. 5.5.2). ${ }^{60}$

\subsection{INDEPENDÊNCIA RESTRITA DOS AUDITORES}

O Código de Governança Corporativa alemão quer que os auditores exerçam suas atividades de uma maneira eficiente e independente. Para a eleição do auditor, o Código recomenda que haja uma divulgação completa das relações profissionais, financeiras e outras que possa haver entre ele e a empresa. Os conflitos de interesse devem ser revelados prematuramente. A empresa de auditoria deve divulgar em que dimensão se prestaram serviços, especialmente no setor de consultoria, para a empresa e para que atividades de consultoria já foram assumidos compromissos para o ano seguinte (Código, art. 7.2.1, $\S 1 .^{\circ}$ ). ${ }^{61} \mathrm{O}$ auditor deve relatar imediatamente ao presidente do Conselho de Administração ou da Comissão de Controle Interno os fundamentos de “exclusão ou rejeição' que possam surgir durante a auditoria, desde que tais fundamentos não possam ser eliminados imediatamente (Código, art. $\left.7.2 .1, \S 2 .^{\circ}\right) .62$

\section{ConClusÃo}

A Comissão Governamental tem se reunido regularmente, apresentando sugestões de adaptação ao Código de Governança Corporativa alemão. A Comissão Européia divulgou seu plano de ação para a modernização da legislação referente às sociedades por ações e para o aperfeiçoamento da governança corporativa. São várias as recomendações da Comissão Européia que a Comissão Governamental tem cogitado incorporar ao Código.

A remuneração dos membros da Diretoria, por exemplo, deve ser adequada e transparente. A Comissão Governamental alemã, seguindo a orientação da Comissão Européia, decidiu especificar ainda mais o previsto no Código, (art. 4.263) no sentido de que haja uma "divulgação individualizada da remuneração da Diretoria e do Conselho de Administração". A remuneração dos membros tanto da Diretoria como do Conselho de Administração deve ser individualizada em seus componentes constitutivos. Deve, por outro lado, passar a haver um teto para as stock options, que corresponda a parâmetros comparativos exigentes e relevantes. Em situações extraordinárias, o Conselho de Administração deve estabelecer limites na emissão de ações, devendo-se divulgar amplamente seu valor.

O sistema de remuneração dos membros da Diretoria e do Conselho de Administração deve ser anunciado na página da internet da sociedade por ações de 
uma maneira que seja compreensível para o público em geral, bem como ter seus fundamentos esclarecidos nos relatórios financeiros da empresa. Outra recomendação da Comissão Européia, que pode ser incorporada ao Código de Governança Corporativa alemão, diz respeito a colocar a Assembléia Geral a par, pormenorizadamente, do sistema de remuneração dos membros da Diretoria e do Conselho de Administração. O próprio presidente do Conselho de Administração deve informar a Assembléia Geral sobre os fundamentos do sistema de remuneração e sobre suas alterações. Essas recomendações servem ao objetivo de conferir mais transparência ao sistema de remuneração vigente nas sociedades por ações. Os acionistas e investidores poderão, assim, verificar se o desempenho daqueles membros é compatível com a remuneração auferida. O sistema de remuneração deve ser efetuado de acordo com componentes fixos, participação nos lucros e gratificações por desempenho de longo prazo. Quando o sistema de remuneração dos membros da Diretoria e do Conselho de Administração for transparente, a própria gestão da empresa será mais racional, e a confiança depositada nela, maior.O Código de Governança Corporativa alemão poderá ser submetido a alterações, com o influxo de novos consensos que forem atingidos sobre o assunto em organizações internacionais. O G-7, o grupo das nações mais ricas do mundo, considera a governança corporativa o mais novo pilar da economia mundial. A OCDE promove, periodicamente, reuniões de discussão e avaliação do assunto. Conjuntamente com o Banco Mundial, a OCDE lançou, em setembro de 1999, o Global Corporate Governance Forum, tendo em mira conferir visibilidade ao tema. Surgiram, em vários países, instituições dedicadas a promover debates sobre governança corporativa.Uma das principais lições do Código de Governança Corporativa alemão reside no fato de que os princípios de governança corporativa, para serem efetivamente colocados em prática de uma maneira universal e cogente, precisam ultrapassar o umbral do soft law para transformarem-se em hard law. Até agora, no Brasil, tem-se encarado a governança corporativa com uma projeção eminentemente ética, de uma ética de resultados. Um dos principais fatores que contribuiriam para que as empresas adotassem os princípios da governança corporativa seria a melhora de sua imagem junto ao mercado. Uma empresa que seguisse os princípios da governança corporativa, para os investidores em potencial, seria mais digna de confiança e, assim, receberia mais investimentos. Recebendo mais investimento, seu valor de mercado aumentaria. A Alemanha, como podemos conferir ao longo deste artigo, transformou os princípios da governança corporativa de soft law em hard law. As sociedades por ações brasileiras, atualmente, têm se beneficiado de um momento poucas vezes vivenciado pela economia internacional. Pode chegar o momento em que, tendo de competir mais acirradamente por investidores nacionais e internacionais, para promover maior confiança em seu funcionamento, seja necessário uniformizar, de maneira obrigatória, o respeito no 


\section{Brasil à governança corporativa com intuito de consolidação do mercado de capi- tais e da proteção dos acionistas minoritários.}

: ARTIGO APROVADO (12/05/2007) : RECEBIDO EM 01/11/2006

\section{NOTAS}

1 Advogado, doutor em direito pela FDUSP, professor universitário.

2 Neste artigo, utilizaremos alternadamente as expressões "sociedade anônima", "sociedade por ações" e "companhia".

3 No Código de Governança Corporativa alemão, utiliza-se o termo "Aufsichtsrat". "Aufsicht" significa supervisão, fiscalização. "Rat", conselho. Aufsichtsrat, portanto, poderia ser traduzido como Conselho de Supervisão, de Fiscalização. Ou, simplesmente, Conselho Fiscal, para aproximar-se da nomenclatura jurídica brasileira. A melhor tradução para Aufsichtsrat, no entanto, sob o ponto de vista funcional, é Conselho de Administração. À luz da Lei das Sociedades Anônimas alemã (Aktiengesetz), art. 84, ele nomeia os membros da Diretoria.

4 O conflito de agência é resultante efetivamente da separação entre a propriedade e a administração da empresa. O titular da propriedade delega ao administrador o poder de decisão sobre a empresa. Os interesses do proprietário nem sempre são idênticos aos do administrador. Para superar o conflito de agência, é necessário que se adotem mecanismos de fiscalização e incentivo que promovam um comportamento da parte dos administradores, dos executivos, que não seja discrepante do interesse dos proprietários da empresa, dos acionistas.

5 Ao utilizar esta expressão, "proprietários das sociedades por ações", procuramos ressaltar, para que se coloque em prática os princípios da governança corporativa, que os acionistas são efetivamente os proprietários das sociedades anônimas. O Conselho de Administração, representando os proprietários das sociedades por ações, os proprietários do capital, deve avaliar e fiscalizar o desempenho da gestão.

6 O Instituto Brasileiro de Governança Corporativa (IBGC), em seu website, dispõe de material sobre o tema (www.ibgc.org.br).

7 Deutscher Corporate Governance Kodex.

8 Aktiengesetz.

9 Transparenz- und Publizitätsgesetz.

10 O previsto no art. 161 da Lei das Sociedades Anônimas alemã será analisado no Capítulo 2 deste artigo.

11 Código de Governança Corporativa alemão, Preâmbulo, item 9: "Der Kodex wird in der Regel einmal jährlich vor dem Hintergrund nationaler und internationaler Entwicklungen überprüft und bei Bedarf angepasst" ( "Item 9: O Código será revisto regularmente uma vez por ano de acordo com o desenvolvimento nacional e internacional, sendo adaptado se for necessário" - tradução livre). 
12 A composição dual diz respeito, neste texto, ao fato de haver uma divisão entre as atividades de direção (Diretoria) e fiscalização (Conselho de Administração) da empresa. Este sistema também é chamado de dualista. No sistema monista, ambas as funções são concentradas em um só órgão (Board of Directors).

13 Gesetz zur Kontrolle und Transparenz im Unternehmensbereich.

14 Wertpapierhandelsgesetz.

15 Handelsgesetzbuch.

16 Mitbestimmungsgesetz.

17 Em conformidade com o princípio comply or explain, que poderia ser traduzido, livremente, como "obedeça ou explique”, as sociedades por ações que não cumprirem o previsto no Código de Governança Corporativa alemão devem declarar por que não adotaram suas recomendações.

18 A Enron, que na década de 1990 do século passado foi uma das mais atrativas empresas de energia do mundo, terminou declarando falência, admitindo haver fraudado seus balanços contábeis para atrair e manter investidores. Houve recentemente vários outros escândalos que também abalaram o mercado financeiro. Podemos citar, por exemplo, os da Parmalat, Tyco e World.Com. Eles, à semelhança do escândalo da Enron, causaram prejuízos aos investidores, abalando sua confiança no mercado de ações.

19 Wertpapiererwebs- und Übernahmegesetz.

20 Tem-se em mente a proposta da Comissão Européia para uma diretriz sobre a aquisição de empresas, de 02.10.2002.

21 Finanzmarktförderungsgesetz.

22 Lei das Sociedades Anônimas alemã, art. 161: "Vorstand und Aufsichtsrat der börsennotierten Gesellschaft erklären jährlich, dass den vom Bundesministerium der Justiz im amtlichen Teil des elektronischen Bundesanzeigers bekannt gemachten Empfehlungen der 'Regierungskommission Deutscher Corporate Governance Kodex' entsprochen wurde und wird oder welche Empfehlungen nicht angewendet wurden oder werden. Die Erklärung ist den Aktionären dauerhaft zugängig zu machen”.

23 Einführungsgesetz zum Aktiengesetz.

24 Remetendo a entrega da declaração prevista no art. 161 da Lei das Sociedades Anônimas a 2002, ressaltamos que a entrada em vigor do Código já é um fato consumado de longa data na Alemanha.

25 Lei de Introdução à Lei das Sociedades Anônimas alemã, art. 15: "Die Erklärung nach § 161 des Aktiengesetzes ist erstmals im Jahre 2002 abzugeben. Sie kann in diesem Jahr aber darauf beschränkt werden, dass den Empfehlungen der 'Regierungskommission Deutscher Corporate Governance Kodex' entsprochen wird oder welche Empfehlungen nicht angewendet werden”.

26 Esta modalidade de comportamento, a compra e venda de ações da empresa por membros da Diretoria e do Conselho de Administração, costuma ser designada como directors dealings.

27 Código de Governança Corporativa alemão, art. 6.6, § 1. ${ }^{\circ}:$ "Erwerb oder Veräußerung von Aktien der Gesellschaft oder von darauf bezogenen Erwerbs- oder Veräußerungsrechten (z. B. Optionen) sowie von Rechten, die unmittelbar vom Börsenkurs der Gesellschaft abhängen, durch Vorstands- und Aufsichtsratsmitglieder der Gesellschaft oder ihres Mutterunternehmens sowie durch bestimmte ihnen nahestehende Personen werden von diesen unverzüglich der Gesellschaft mitgeteilt. Von der Mitteilungspflicht sind der Erwerb auf arbeitsvertraglicher Grundlage, als Vergütungsbestandteil sowie unwesentliche Erwerbs- und Veräußerungsgeschäfte (25.000,EURO in 30 Tagen) ausgenommen. Die Gesellschaft veröffentlicht die Mitteilung unverzüglich" ("Art. 6.6, § 1. ${ }^{\circ}$ : A compra ou venda de ações da sociedade ou de direitos de compra ou venda respectivos (por exemplo, opções), bem como de direitos que dependam diretamente da cotação em bolsa da sociedade, através de membros da Diretoria ou do Conselho de Administração da sociedade ou de sua empresa-mãe, bem como através de pessoas próximas a eles, serão imediatamente comunicadas por estes à sociedade. Ficam excluídas do dever de comunicação a compra prevista em contrato de trabalho, como parte integrante da remuneração, bem como a compra ou venda não relevantes (25.000,- EUROS em 30 dias). A sociedade publicará imediatamente a comunicação" - tradução livre). 
28 O princípio one share, one vote remete ao lema da Revolução americana - one man, one vote.

29 Código de Governança Corporativa alemão, art. 2.3.3: "Die Gesellschaft soll den Aktionären die persönliche Wahrnehmung ihrer Rechte erleichtern. Auch bei der Stimmrechtsvertretung soll die Gesellschaft die Aktionäre unterstützen. Der Vorstand soll für die Bestellung eines Vertreters für die weisungsgebundene Ausübung des Stimmrechts der Aktionäre sorgen; dieser sollte auch während der Hauptversammlung erreichbar sein” "“Art. 2.3.3: A sociedade deverá facilitar o exercício pessoal pelos acionistas de seus direitos. A sociedade também deverá apoiar os acionistas na representação do direito de voto. A Diretoria deverá cuidar para que seja nomeado um representante para o exercício do direito de voto dos acionistas, de acordo com as instruções destes. Também deve ser prevista a possibilidade de contatá-lo durante a Assembléia Geral” - tradução livre).

30 Código de Governança Corporativa alemão, art. 2.3.4: "Die Gesellschaft sollte den Aktionären die Verfolgung der Hauptversammlung über moderne Kommunikationsmedien (z.B. Internet) ermöglichen" ( "Art. 2.3.4: A sociedade deve possibilitar aos acionistas acompanhar a Assembléia Geral mediante meios modernos de comunicação (por exemplo, a internet” tradução livre).

31 Código de Governança Corporativa alemão, art. 3.7, § 3. ${ }^{\circ}$ : "In angezeigten Fällen sollte der Vorstand eine außerordentliche Hauptversammlung einberufen, in der die Aktionäre über das Übernahmeangebot beraten und gegebenenfalls über gesellschaftsrechtliche Maßnahmen beschließen" ( "Art. 3.7, § 3. : Nos casos oportunos, a Diretoria deve convocar uma Assembléia Extraordinária, na qual os acionistas debatam a oferta de aquisição e, se for necessário, decidam as medidas societárias legais a serem colocadas em prática” - tradução livre).

\section{Vorstand.}

33 Vorsitzender.

34 Aufsichtsrat.

35 Vorstandsvorsitzender.

36 Directoire.

37 Conseil de surveillance.

38 No Verwaltungsratsystem, vige explicitamente a composição dual da direção das sociedades anônimas, com Diretoria e Conselho de Administração.

39 Código de Governança Corporativa alemão, art. 3.4, § 1. : "Die ausreichende Informationsversorgung des Aufsichtsrats ist gemeinsame Aufgabe von Vorstand und Aufsichtsrat" ( Art. 3.4, § 1. ${ }^{\circ}$ : O fornecimento amplo da informação do Conselho de Administração é uma atribuição conjunta da Diretoria e do Conselho de Administração" - tradução livre).

40 Código de Governança Corporativa alemão, art. 5.3.: "Bildung von Ausschüssen" ( "Art. 5.3: Formação de Comissões" - tradução livre).

41 A título de terceiros, pode-se pensar nos trabalhadores das empresas.

42 Código de Governança Corporativa alemão, art. 7.1.1: "Anteilseigner und Dritte werden vor allem durch den Konzernabschluss informiert. Sie sollen während des Geschäftsjahres durch Zwischenberichte unterrichtet werden. Der Konzernabschluss und die Zwischenberichte sollen unter Beachtung international anerkannter Rechnungslegungsgrundsätze aufgestellt werden. Für gesellschaftsrechtliche Zwecke (Ausschüttungsbemessung, Gläubigerschutz) werden Jahresabschlüsse nach nationalen Vorschriften (HGB) aufgestellt, die auch Grundlage für die Besteuerung sind" ("Art. 7.1.1: Acionistas e terceiros serão informados sobretudo através do balanço consolidado da empresa. Eles deverão ser informados durante o ano fiscal através de relatórios parciais. O balanço consolidado da empresa e os relatórios parciais deverão ser redigidos levando em consideração princípios de contabilidade reconhecidos internacionalmente. Para fins da normativa societária (cálculo de dividendos, proteção dos credores), o balanço anual será redigido de acordo com o previsto na normativa nacional (Código Comercial), que também é base para a tributação" tradução livre). 
43 Código de Governança Corporativa alemão, art. 3.5, § 1. ${ }^{\circ}$ : "Gute Unternehmensführung setzt eine offene Diskussion zwischen Vorstand und Aufsichtsrat sowie in Vorstand und Aufsichtsrat voraus. Die umfassende Wahrung der Vertraulichkeit ist dafür von entscheidender Bedeutung" ( "Art. 3.5, § 1. ${ }^{\circ}$ : A boa direção da empresa pressupõe um diálogo aberto entre a Diretoria e o Conselho de Administração, bem como na Diretoria e no Conselho de Administração. A observação estrita da confidencialidade é, para tanto, de importância decisiva" - tradução livre).

44 As repetições da expressão "Conselho de Administração", nesta última frase, obedecem ao disposto no texto original. Quando, ao longo deste artigo, outros termos forem repetidos, tal repetição também corresponderá sempre ao previsto originalmente no Código de Governança Corporativa alemão.

45 Código de Governança Corporativa alemão, art. 5.2: “Aufgaben und Befugnisse des Aufsichtsratsvorsitzenden, § $3 .^{\circ}$ Der Aufsichtsratsvorsitzende soll mit dem Vorstand, insbesondere mit dem Vorsitzenden bzw. Sprecher des Vorstands, regelmäßig Kontakt halten und mit ihm die Strategie, die Geschäftsentwicklung und das Risikomanagement des Unternehmens beraten. Der Aufsichtsratsvorsitzende wird über wichtige Ereignisse, die für die Beurteilung der Lage und Entwicklung sowie für die Leitung des Unternehmens von wesentlicher Bedeutung sind, unverzüglich durch den Vorsitzenden bzw. Sprecher desVorstands informiert. Der Aufsichtsratsvorsitzende soll sodann den Aufsichtsrat unterrichten und erforderlichenfalls eine außerordentliche Aufsichtsratssitzung einberufen".

46 Código de Governança Corporativa alemão, art. 7.1.1: "Anteilseigner und Dritte werden vor allem durch den Konzernabschluss informiert. Sie sollen während des Geschäftsjahres durch Zwischenberichte unterrichtet werden. Der Konzernabschluss und die Zwischenberichte sollen unter Beachtung international anerkannter Rechnungslegungsgrundsätze aufgestellt werden. Für gesellschaftsrechtliche Zwecke (Ausschüttungsbemessung, Gläubigerschutz) werden Jahresabschlüsse nach nationalen Vorschriften (HGB) aufgestellt, die auch Grundlage für die Besteuerung sind".

47 Código de Governança Corporativa alemão, art. 7.1.2: "Der Konzernabschluss wird vom Vorstand aufgestellt und vom Abschlussprüfer sowie vom Aufsichtsrat geprüft. Der Konzernabschluss soll binnen 90 Tagen nach Geschäftsjahresende, die Zwischenberichte sollen binnen 45 Tagen nach Ende des Berichtszeitraums, öffentlich zugänglich sein" ( "Art. 7.1.2: O balanço consolidado da empresa será redigido pela Diretoria e examinado pelo auditor revisor e pelo Conselho de Administração. O balanço consolidado da empresa deverá ser colocado à disposição do público dentro de 90 dias após o final do ano fiscal, os relatórios parciais deverão ser colocados à disposição do público dentro de 45 dias após o final do respectivo período" - tradução livre).

48 Código de Governança Corporativa alemão, art. 6.4: "Zur zeitnahen und gleichmäßigen Information der Aktionäre und Anleger soll die Gesellschaft geeignete Kommunikationsmedien, wie etwa das Internet, nutzen” ( "Art. 6.4: Para a informação tempestiva e consistente dos acionistas e investidores, a sociedade deverá utilizar meios de comunicação adequados, como a internet" - tradução livre).

49 Código de Governança Corporativa alemão, art. 4.2.2, § 2. ${ }^{\circ}$ : "Die Vergütung der Vorstandsmitglieder wird vom Aufsichtsrat unter Einbeziehung von etwaigen Konzernbezügen in angemessener Höhe auf der Grundlage einer Leistungsbeurteilung festgelegt. Kriterien für die Angemessenheit der Vergütung bilden insbesondere die Aufgaben des jeweiligen Vorstandsmitglieds, seine persönliche Leistung, die Leistung des Vorstands sowie die wirtschaftliche Lage, der Erfolg und die Zukunftsaussichten des Unternehmens unter Berücksichtigung seines Vergleichsumfelds" ( "Art. 4.2.2, § 2. : A remuneração dos membros da Diretoria será fixada pelo Conselho de Administração, levando em consideração quaisquer rendimentos percebidos na empresa, numa dimensão adequada, com base numa avaliação de desempenho. Critérios para a adequação da remuneração são, especialmente, as atribuições dos respectivos membros da Diretoria, seu desempenho pessoal, o desempenho da Diretoria, bem como a situação econômica, os resultados e as previsões quanto ao futuro da empresa, levando em consideração as empresas em funcionamento no mesmo setor" tradução livre).

50 As stock options são uma modalidade de remuneração efetuada por sociedades anônimas. Essencialmente, dizem respeito a uma opção de compra de uma ação da empresa. Este sistema permite que os dirigentes e empregados adquiram suas ações numa data e com um preço fixado antecipadamente. Os dirigentes e empregados são, então, estimulados a agir no sentido de aumentar o valor de mercado da sociedade anônima. As stock options podem ser utilizadas para atrair e manter talentos na empresa, ao permitir que empregados, após um certo período de atividade na empresa ou com o cumprimento de determinadas metas, possam adquirir ações a um preço prefixado. O empregado poderá adquiri-las a um preço relativamente baixo para vendê-las por um preço mais alto quando a sociedade anônima estiver mais valorizada no mercado.

51 Phantom stocks, ou ações-fantasma, são adotadas por empresas de capital fechado, ou por aquelas que não querem oferecer ações negociadas na bolsa de valores. 
52 Código de Governança Corporativa alemão, art. 4.2.3, § 2. : "Als variable Vergütungskomponenten mit langfristiger Anreizwirkung und Risikocharakter dienen insbesondere Aktien der Gesellschaft mit mehrjähriger Veräußerungssperre, Aktienoptionen oder vergleichbare Gestaltungen (z.B. Phantom Stocks). Aktienoptionen und vergleichbare Gestaltungen sollen auf anspruchsvolle, relevanteVergleichsparameter bezogen sein. Eine nachträgliche Änderung der Erfolgsziele oder der Vergleichsparameter soll ausgeschlossen sein. Für außerordentliche, nicht vorhergesehene Entwicklungen soll der Aufsichtsrat eine Begrenzungsmöglichkeit (Cap) vereinbaren" ( “Art. 4.2.3, § 2. : Como componentes varáveis da remuneração com efeito de incentivo a longo prazo e caráter de risco, constituem exemplo, especialmente, as ações da sociedade com bloqueio plurianual à alienação, stock options ou instrumentos análogos (por exemplo, phantom stocks). Stock options ou instrumentos análogos deverão referir-se a parâmetros de comparação exigentes e relevantes. A alteração posterior dos objetivos ou dos parâmetros de comparação deverá ser excluída. Para desenvolvimentos extraordinários e imprevisíveis, o Conselho de Administração deverá acordar uma possibilidade de limitação (Cap)" - tradução livre).

\section{Wertpapier.}

54 Código de Governança Corporativa alemão, art. 4.2.4: "Die Vergütung der Vorstandsmitglieder soll im Anhang des Konzernabschlusses aufgeteilt nach Fixum, erfolgsbezogenen Komponenten und Komponenten mit langfristiger Anreizwirkung ausgewiesen werden. Die Angaben sollen individualisiert erfolgen" ( "Art. 4.2.4:A remuneração dos membros da Diretoria deverá ser estabelecida no anexo do balanço consolidado da empresa, com indicação separada dos componentes fixos e daqueles relacionados a rendimento e a incentivo de longo prazo. Os dados deverão ser individualizados" - tradução livre).

55 Código de Governança Corporativa alemão, art. 5.4.5, § 2. ": "Die Mitglieder des Aufsichtsrats sollen neben einer festen eine erfolgsorientierte Vergütung erhalten. Die erfolgsorientierte Vergütung sollte auch auf den langfristigen Unternehmenserfolg bezogene Bestandteile enthalten" ( "Art. 5.4.5, § 2. ${ }^{\circ}$ : Os membros do Conselho de Administração deverão receber uma remuneração fixa e uma remuneração orientada pelo desempenho. A remuneração orientada pelo desempenho também deve conter componentes relacionados ao resultado de longo prazo da empresa”- tradução livre).

56 Código de Governança Corporativa alemão, art. 5.4.2: "Eine unabhängige Beratung und Überwachung des Vorstands durch den Aufsichtsrat wird auch dadurch ermöglicht, dass dem Aufsichtsrat nicht mehr als zwei ehemalige Mitglieder des Vorstands angehören sollen und dass Aufsichtsratsmitglieder keine Organfunktionen oder Beratungsaufgaben bei wesentlichen Wettbewerbern des Unternehmens ausüben sollen" ( "Art. 5.4.2: A consultoria e controle independentes da Diretoria pelo Conselho de Administração também serão proporcionados, de maneira que não deverão pertencer ao Conselho de Administração mais do que dois ex-membros da Diretoria. Os membros do Conselho de Administração não deverão exercer nenhuma função diretiva nem de consultoria em concorrentes importantes da empresa" - tradução livre).

57 Código de Governança Corporativa alemão, art. 5.2: “Aufgaben und Befugnisse des Aufsichtsratsvorsitzenden, $\S 2 .^{\circ}:$ Der Aufsichtsratsvorsitzende soll zugleich Vorsitzender der Ausschüsse sein, die die Vorstandsverträge behandeln und die Aufsichtsratssitzungen vorbereiten. Den Vorsitz im Prüfungsausschuss (Audit Committee) sollte er nicht innehaben” ("Art. 5.2: Atribuições e competências do presidente do Conselho de Administração, § 2. : O presidente do Conselho de Administração deverá ser ao mesmo tempo presidente das comissões que tratam dos contratos da Diretoria e que preparam as reuniões do Conselho de Administração. Ele não deve ser presidente da Comissão de Controle Interno" - tradução livre).

58 Código de Governança Corporativa alemão, art. 5.3.2: "Der Aufsichtsrat soll einen Prüfungsausschuss (Audit Committee) einrichten, der sich insbesondere mit Fragen der Rechnungslegung und des Risikomanagements, der erforderlichen Unabhängigkeit des Abschlussprüfers, der Erteilung des Prüfungsauftrags an den Abschlussprüfer, der Bestimmung von Prüfungsschwerpunkten und der Ho-norarvereinbarung befasst. Der Vorsitzende des Prüfungsausschusses sollte kein ehemaliges Vorstandsmitglied der Gesellschaft sein" ( "Art. 5.3.2: O Conselho de Administração deverá estabelecer uma Comissão de Controle Interno que se encarregue, especialmente, das questões referentes à contabilidade e à gestão dos riscos, à independência exigida do auditor revisor, à atribuição do cargo de revisão ao auditor, à determinação dos pontos-chave de revisão e dos honorários. O presidente da Comissão de Controle Interno não deve ter sido ex-membro da Diretoria da sociedade" - tradução livre).

59 Código de Governança Corporativa alemão, art. 5.4.3: "Jedes Aufsichtsratsmitglied achtet darauf, dass ihm für die Wahrnehmung seiner Mandate genügend Zeit zur Verfügung steht. Wer dem Vorstand einer börsennotierten Gesellschaft angehört, soll insgesamt nicht mehr als fünf Aufsichtsratsmandate in konzernexternen börsennotierten Gesellschaften wahrnehmen" ("Art. 5.4.3: Todo membro de Conselho de Administração deverá ter à disposição tempo suficiente para o exercício de seu mandato. Quem pertence à Diretoria de uma sociedade por ações não deverá exercer ao todo mais do que cinco mandatos em Conselhos de Administração em outras sociedades por ações estranhas à empresa” - tradução livre). 
60 Código de Governança Corporativa alemão, art. 5.5.2: "Jedes Aufsichtsratsmitglied soll Interessenkonflikte, insbesondere solche, die auf Grund einer Beratung oder Organfunktion bei Kunden, Lieferanten, Kreditgebern oder sonstigen Geschäftspartnern entstehen können, dem Aufsichtsrat gegenüber offenlegen" ( "Art. 5.5.2: Todo membro do Conselho de Administração deverá informar conflitos de interesse ao Conselho de Administração, especialmente aqueles que possam surgir com base na consultoria ou função diretiva junto a clientes, fornecedores, credores ou outros parceiros de negócio” - tradução livre).

61 Código de Governança Corporativa alemão, art. 7.2.1, § 1. ${ }^{\circ}$ : "Vor Unterbreitung des Wahlvorschlags soll der Aufsichtsrat bzw. der Prüfungsausschuss eine Erklärung des vorgesehenen Prüfers einholen, ob und ggf. welche beruflichen, finanziellen oder sonstigen Beziehungen zwischen dem Prüfer und seinen Organen und Prüfungsleitern einerseits und dem Unternehmen und seinen Organmitgliedern andererseits bestehen, die Zweifel an seiner Unabhängigkeit begründen können. Die Erklärung soll sich auch darauf erstrecken, in welchem Umfang im vorausgegangenen Geschäftsjahr andere Leistungen für das Unternehmen, insbesondere auf dem Beratungssektor, erbracht wurden bzw. für das folgende Jahr vertraglich vereinbart sind" ("Art. 7.2.1, § $1 .^{\circ}$ : Antes de submeter uma proposta de eleição, o Conselho de Administração ou a Comissão de Controle Interno deverão obter uma declaração do auditor que se tem em vista com respeito às relações profissionais, financeiras ou de outra natureza que existam entre a empresa de auditoria, seus órgãos e seus diretores de auditoria, de um lado, e a sociedade e os membros de seus órgãos, de outro lado, que possam suscitar dúvidas com relação à sua independência. A declaração deverá especificar em que medida, no ano fiscal anterior, outras atividades, especialmente no setor de consultoria, foram desempenhadas para a empresa, e se tais atividades foram acordadas contratualmente para o ano seguinte” - tradução livre).

62 Código de Governança Corporativa alemão, art. 7.2.1, § 2. ${ }^{\circ}$ : "Der Aufsichtsrat soll mit dem Abschlussprüfer vereinbaren, dass der Vorsitzende des Aufsichtsrats bzw. des Prüfungsausschusses über während der Prüfung auftretende mögliche Ausschluss- oder Befangenheitsgründe unverzüglich unterrichtet wird, soweit diese nicht unverzüglich beseitigt werden" ("Art. 7.2.1, $\S 2 .^{\circ}$ : O Conselho de Administração deverá entrar em acordo com o auditor revisor, no sentido de que o presidente do Conselho de Administração ou da Comissão de Controle Interno sejam informados imediatamente sobre circunstâncias que surjam durante a atividade de auditoria que possam suscitar a exclusão ou rejeição do auditor, desde que elas não possam ser eliminadas imediatamente" - tradução livre).

63 Código de Governança Corporativa alemão, art. 4.2: "Zusammensetzung und Vergütung" ( "Art. 4.2: Composição e remuneração" - tradução livre).

\section{REFERÊNCIAS BIBLIOGRÁFICAS}

ALEMANHA. Regierungskommission Deutscher Corporate Governance Kodex. Ausführungen von Dr. Gerhard Cromme Vorsitzender der Regierungskommission Deutscher Corporate-Kodex anlässlich der Veröffentlichung des Entwurfs Deutscher Corporate Governance-Kodex am 18. Dez. 2001 in Düsseldorf, Berlim, 2001. . Ausführungen von Dr. Gerhard Cromme. Vorsitzender der Regierungskommission Deustscher Corporate Governance-Kodex anlässlich der Pressekonferenz nach Übergabe des Deutschen Corporate Governance-Kodex an die Bundesministerin der Justiz Frau Prof. Dr. Herta Däubler-Gmelin am 26. Februar 2002 in Berlin, Berlim, 2002.

. Deutscher Corporate Governance Kodex, Berlim, 2003.

Mitteilung für die Presse nr. 9/02 Berlin, am 26 Februar 2002. Kodex macht deutsche Unternehmen fit für die internationalen Finanzmärkte. Klare Verhaltensstandards für Transparenz und Vertrauen in deutschen Unternehmen, Berlim, 2002.

. Mitteilung für die Presse, am 8. Nov. 2002, Berlim, 2002.

. Mitteilung für die Presse, am 21. Mai 2003, Berlim, 2003.

-. Transparenz und Publizitätsgesetz in Kraft getreten, Berlim, 2003.

BAYERISCHE HYPO- UND VEREINSBANK AKTIENGESELLCHAFT. Erklärung zum Deutschen Corporate Governance Codex, Munique, 2 Dez. 2003.

HAKELMACHER, Sebastian. Corporate Governance oder Die korpulente Gouvernante. 2. ed. Colônia: Otto Schmidt, 2005.

HILB, Martin. Integrierte Corporate Governance. Ein neues Konzept der Unternehmensführung und Erfolgskontrolle: Ein Neues Konzept Der Unternehmensfuhrung Und Erfolgskontrolle. 2. ed. Berlim: Springer, 2006. 
048 : A PROTEÇÃO AO INVESTIDOR NO CÓDIGO DE GOVERNANÇA CORPORATIVA ALEMÃO

HOMMELHOFF, Peter; HOPT, Klaus J.; WERDER, Axel von. Handbuch Corporate Governance. Colônia, Otto Schmidt, 2003.

KUCK, Dieter. Aufsichtsräte und Beiräte in Deutschland. Rahmenbedingungen, Anforderungen, professionelle Auswahl. Wiesbaden: Gabler, 2006.

MALIK, Fredmund. Corporate Governance und Unternehmenspolitik. Von der richtigen und guten Führung. Frankfurt: Campus Verlag GmbH, 2007.

- Die Neue Corporate Governance. Richtiges Top-Management - Wirksame Unternehmensaufsicht. 3. ed. Frankfurter Allgemeine Buch, 2002.

MENZIES, Christof. Sarbanes-Oxley Act. Professionelles Management interner Kontrollen. Stuttgart: SchäfferPoeschel, 2004.

PASALIC, Mario. Der Deutsche Corporate Governance Kodex. Die Akzeptanz und Umsetzung bei börsennotierten Gesellschaften. Saarbrücken: Verlag Dr. Müller, 2007.

SCHEWE, Gerhard. Unternehmensverfassung: Corporate Governance Im Spannungsfeld Von Leitung, Kontrolle Und Interessenvertretung. Berlim: Springer, 2005.

Roberto de A. Chacon de Albuquerque

Professor da Universidade Católica de Brasília, Brasil DOUTOR EM DIREITO PELA USP, BRASIL 